\title{
Mapping Human Subsistence in West Africa (1000 BC - AD 1500)
}

\author{
Andrea U. Kay, L.N. Phelps and J.O. Kaplan \\ Les Rasses, Switzerland, 2-6 November 2015
}

PAGES' LandCover6k working group aims to better understand the development and present state of global ecosystems as influenced by climate change and humans during the late Holocene. The interdisciplinary working group joins archaeologists with ecosystem modelers and paleoecologists to map land-cover and land-use change over the last 6000 years. This workshop was convened by LandCover6k members who are studying sub-Saharan Africa, a region that has been only superficially treated in most previous large-scale synthesis work, and whose researchers have been underrepresented in international collaborations.

The workshop focused on land-use change during the critical period of the African Iron Age transition (1000 BC-1500 AD) which is marked not only by the spread of agriculture and pastoralism across most of sub-Saharan Africa, but also by the development of mod ern African climate following the end of the African Humid Period.

The central methodology of LandCover6k is to employ archaeological and paleoecological archives to reconstruct past land cover and land use. Land use is not only influenced by environment but also is a product of historical, cultural, and societal factors that cannot be easily predicted. Kay and Kaplan (2015) therefore proposed a categorization of livelihoods in Iron Age Africa. Each category encompasses the subsistence, trade, technology, and political organization of societies that may be identified in archaeological and historical records. With this classification scheme, we set out to map the occurrence of the livelihood categories in space and time. We decided that a more focused case-study area would facilitate the mapping process, so West and Central Africa were chosen to test this process.

The goal of the ACACIA/LandCover6k workshop was to assemble experienced and early-career researchers who study West and Central Africa. Twenty-four researchers representing 14 institutions in nine countries set out to critique and improve both the existing classification system and a prototype set of maps. Assembling this group - experts in a range of fields including paleoecology, linguistics, archaeology, archaeobotany, archaeozoology, human geography, and modeling - in the same room for a focused discussion of the issues and best practices was the optimal way to address the questions set forth by our project.

The workshop was structured around presentations by participants in plenary, informal discussion sessions, and breakout workgroups. The workgroups were divided between live-editing sessions where we worked on the livelihood maps and a discussion group focused on pastoral systems. One of the first developments to emerge from the plenary discussions was the need to revise the classification system; in some cases, this meant consolidating the existing

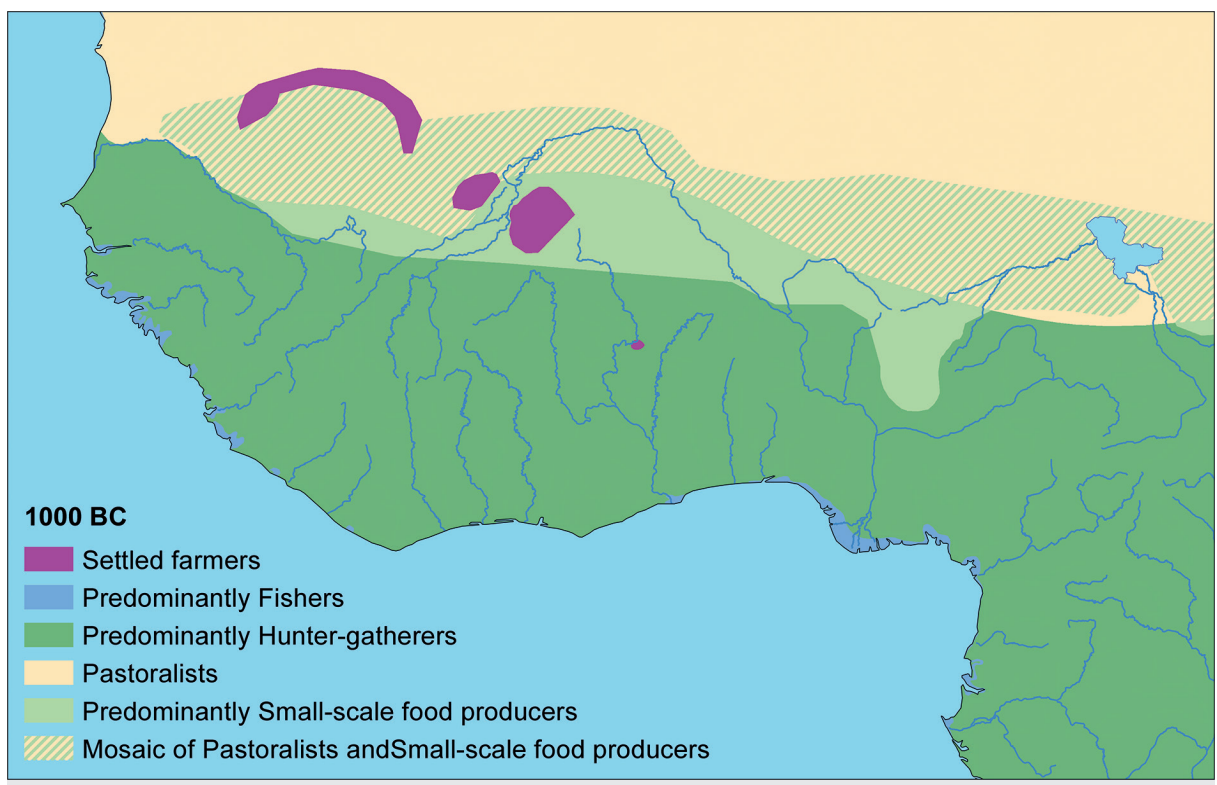

- Hunter-gatherers

- Fishers

- Small-scale food producers

- Settled farmers

- Diversified farmers

- Intensive diversified farmers

- Wetland farmers

- Upland rice farmers

- Pastoralists*

- Industrial production centers* *to be further revised and defined in future

Box 1: Revised classification scheme for West and Central Africa

categories, but also adding new ones. For example, the former category called "Neolithic farmers" has been combined with the "Forager-horticulturalist" category, since the primary difference between the two was the type of crops being used, which is more environmentally than culturally determined. The combined category is now called Smallscale food producers (see Box 1). In addition to the categories revised above, we decided that political entities and their spheres of influence, metallurgical presence/ubiquity/ industry, and domestic animal species distributions should be mapped in separate layers, independent of the agricultural categories.

Mapping progress was made on several time slices, and a temporary pastoralism polygon (Fig. 1) was put in place until an improved version can be developed. Several plans were made for continued work including office visits in 2016, and collaboration on the publication of the final mapset and a database of African archaeological site data. There was also discussion on the planning of a pastoralism workshop in 2016, where pastoral experts will come together for a critical analysis of basic layers, and to incorporate more specialist knowledge in cultural and subsistence overlays.

\section{ACKNOWLEDGEMENTS}

Funding for this workshop was provided by PAGES and the Swiss National Science Foundation.

\section{AFFILIATIONS}

Institute of Earth Surface Dynamics, University of Lausanne, Switzerland

\section{CONTACT}

Andrea U.Kay: Andrea.Kay@unil.ch

Figure 1: Simplified map of lifestyle category distribution for $1000 \mathrm{BC}$ time slice. 